\title{
Development of a context model to prioritize drug safety alerts in CPOE systems
}

\author{
Daniel Riedmann ${ }^{1 \dagger}$, Martin Jung ${ }^{1 \dagger}$, Werner $O$ Hackl ${ }^{1}$, Wolf Stühlinger ${ }^{2}$, Heleen van der Sijs $^{3}$ and \\ Elske Ammenwerth ${ }^{1 *}$
}

\begin{abstract}
Background: Computerized physician order entry systems (CPOE) can reduce the number of medication errors and adverse drug events (ADEs) in healthcare institutions. Unfortunately, they tend to produce a large number of partly irrelevant alerts, in turn leading to alert overload and causing alert fatigue. The objective of this work is to identify factors that can be used to prioritize and present alerts depending on the 'context' of a clinical situation.

Methods: We used a combination of literature searches and expert interviews to identify and validate the possible context factors. The internal validation of the context factors was performed by calculating the inter-rater agreement of two researcher's classification of 33 relevant articles.

Results: We developed a context model containing 20 factors. We grouped these context factors into three categories: characteristics of the patient or case (e.g. clinical status of the patient); characteristics of the organizational unit or user (e.g. professional experience of the user); and alert characteristics (e.g. severity of the effect). The internal validation resulted in nearly perfect agreement (Cohen's Kappa value of 0.97).

Conclusion: To our knowledge, this is the first structured attempt to develop a comprehensive context model for prioritizing drug safety alerts in CPOE systems. The outcome of this work can be used to develop future tailored drug safety alerting in CPOE systems.
\end{abstract}

\section{Background}

Medication errors and adverse drug events (ADEs)

"Errare humanum est - To err is human". This famous quotation, derived from Cicero and Seneca the Elder, is universally applicable, including medicine. Medication errors have been identified to be a common type of medical errors [1]. The Institute of Medicine reports that a hospital patient can expect to be subject to at least one medication error per day [2].

Medication errors and adverse drug events (ADEs) can occur during every step of the medication use process [2-4]. The Council of Europe defines a medication error as "any preventable event that may cause or lead to inappropriate medication use or patient harm while the medication is in the control of the health care professional,

\footnotetext{
*Correspondence: elske.ammenwerth@umit.at

+ Contributed equally

${ }^{1}$ Institute of Health Informatics, UMIT - University for Health Sciences, Medical Informatics and Technology, Eduard Wallnöfer-Zentrum I, Hall in Tirol, Austria

Full list of author information is available at the end of the article
}

patient or consumer" [3] (p.7) and an ADE as "any injury occurring during the patient's drug therapy and resulting either from appropriate care or from unsuitable or suboptimal care" [3] (p.1). ADEs associated with a medication error are considered to be preventable ADEs [2,3].

A further breakdown of medication errors into the five stages of the medication use process, which are prescribing, transcribing/documenting, dispensing, administering, and monitoring, allows the identification of error-prone steps. 39\% [1] of all medication errors and $56 \%$ [5] - 71\% [6] of preventable ADEs occur in the prescription phase.

\section{CPOE to prevent medication errors and ADEs}

There is evidence for the effectiveness of computerized physician order entry (CPOE) in hospital settings in reducing medication errors as well as ADEs [2,7-10]. CPOE systems can be equipped with further clinical decision support (CDS). Kuperman et al. distinguishes between basic (e.g. offers drug-drug interaction checking) and advanced (e.g. includes advanced guidance for 
laboratory testing) medication-related decision support [11]. A systematic review performed in 2008 reported a higher relative risk reduction of medication errors of systems with advanced CDS compared to CPOE systems with limited or no CDS [8].

\section{CPOE and the challenge of alert fatigue}

When a CPOE system is equipped with CDS, the burden of alert-handling has to be considered. As research shows, drug safety alerts as well as reminders from CDS systems are often disregarded by the prescribers. A review paper in 2006 reported alert override-rates of $49 \%$ to $96 \%$ [12]. Especially drug-drug interaction (DDI) and drug-allergy checking suffers from low specificity due to too many false positive warnings which results in high override-rates $[11,12]$. However, in general, all types of CDS-triggered warnings are frequently overridden [12].

Alert fatigue is a frequent complaint about CPOE systems with CDS [12-14]. An increasing number of drug safety alerts has the potential for user desensitization [15]. This desensitization leads to an override of both important (even highly important) and unimportant warnings [12]. In this work we focus on the definition of van der Sijs [16] who describes alert fatigue as the mental state that is the result of alerts consuming too much time and mental energy, which can cause relevant alerts to be unjustifiably overridden along with clinically unimportant ones. Synonyms used for the term alert fatigue are 'cry wolf syndrome' and 'pop-up fatigue' [15].

A systematic review by Khajouei et al. of the design aspects of CPOE systems reported eight studies investigating the impact of specificity, sensitivity, unclear information content, and timing of warnings on creating conditions for medication errors [14]. This review showed that low alert specificity/sensitivity and unclear information content can induce alert fatigue.

\section{A context-aware CPOE system}

Suggestions to improve the specificity of drug safety alerts such as patient-tailored drug safety alerts can be embraced by the term 'context'.

In computer science, 'context' refers to the idea of systems sensing and reacting based on their environment. Within this work, the following definition from the area of ubiquitous computing is used: "Context is any information that can be used to characterize the situation of an entity. An entity is a person, place, or object that is considered relevant to the interaction between a user and an application, including the user and applications themselves" [17] (p.3). A system using 'context' tries to make assumptions about the current situation and circumstances. Dey further designates a system as a contextaware system "if it uses context to provide relevant information and/or services to the user, where relevancy depends on the user's task" [17] (p.4). According to this declaration, context-aware CPOE systems provide:

- Relevant information: for example, context-aware CPOE may prioritize drug safety alerts in order to present them in an adequate manner (life-threatening alerts interrupt the prescribing process of the user and cannot be ignored; in contrary, less relevant alerts are not interrupting the user)

- Relevant services: for example, context-aware CPOE may give reminders for regular laboratory monitoring or may offer drug dosing support.

Figure 1 schematically shows the concept of drug prescription within a CPOE system that prioritizes and presents drug safety alerts depending on the clinical context.

The European PSIP project (Patient Safety through Intelligent Procedures in medication, http://www.psipproject.eu) develops, among others, innovative and CDS systems to increase medication safety during prescription. In the PSIP project, the frequency of ADEs has been analysed for individual medical departments or hospitals. Based upon this knowledge, a rule-based CDS system has been developed [18]. However, so far it has not been exhaustively studied which possible context factors could be used to improve the specificity and sensitivity of drug safety alerts.

\section{Study question}

- What are possible factors that can help to prioritize and present drug safety alerts in CPOE systems according to the given context?

\section{Methods}

The methods used during the creation of the context model can be grouped into three major parts: a factor identification phase, a model generation phase and a model validation phase (see Figure 2).

\section{Phase 1: Identification of context factors}

We combined a literature search with expert interviews to identify the possible context factors that might be used to prioritize and present drug safety alerts.

\section{Literature search}

The literature search aimed at identifying articles dealing with contextualization or the improvement of drug safety alerting in CPOE systems. Two different search strategies were applied:

First, as a starting point, a hand search was performed to extract ideas for contextualized drug safety alerts in CPOE systems which focused on ten journals in the field of health informatics (for a list of all hand- 


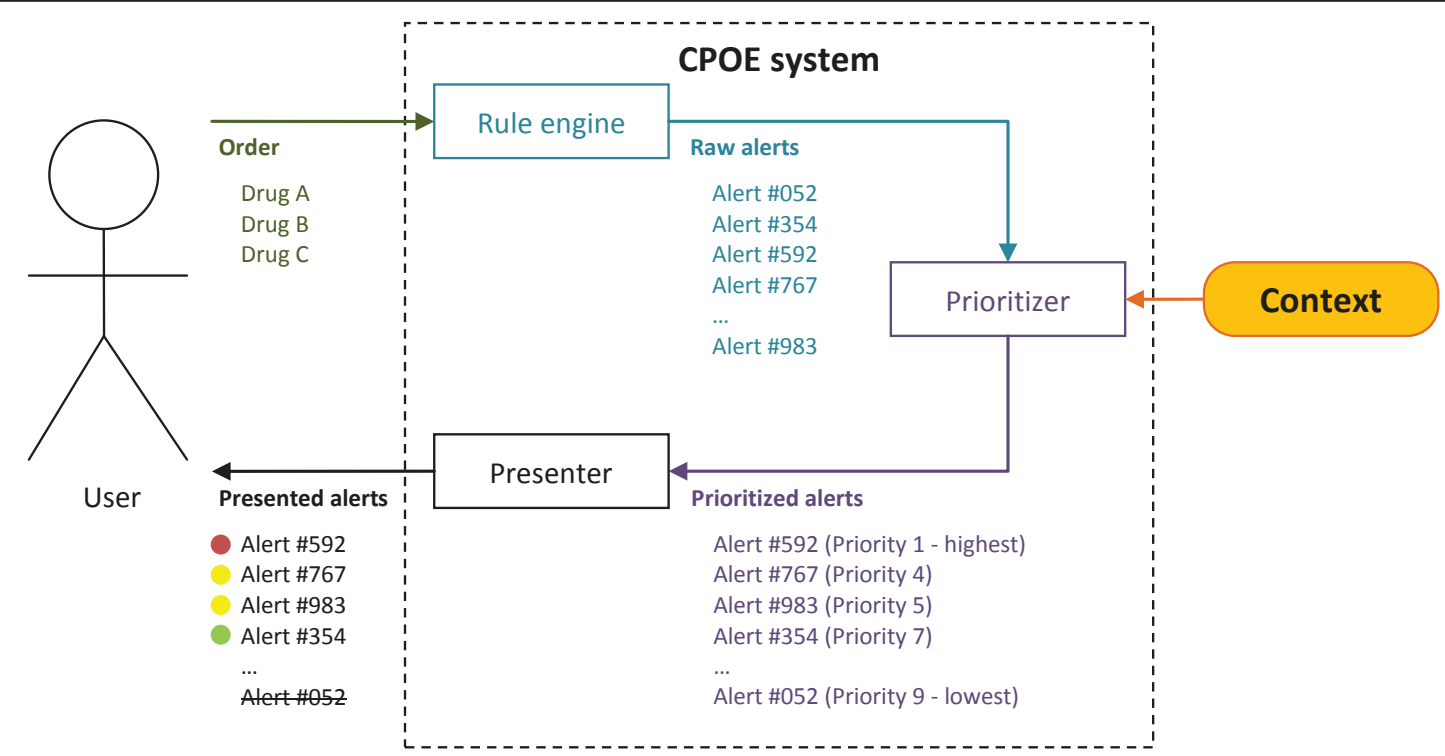

Figure $1 \mathrm{~A}$ context-aware CPOE system. Depending on the prescription, the rule engine of the CDS system generates raw alerts (e.g. drugdrug interaction between acetylsalicylic acid and an anticoagulant). These raw alerts are then prioritized based on context information (e.g. the dose, the age of the patient, any co-medication, or information on user or clinical department). Afterwards, the alerts are presented differently to the user according to their priority (e.g. life-threatening alerts interrupt the prescribing process and cannot be overridden).

searched journals see additional files 1). Two researchers (MJ and DR) carried out this search at the end of February 2010. References of the found papers were followed in order to identify further papers. The researchers also retrieved related articles of found papers, as identified by this function in PubMed.

Second, a PubMed search was conducted comprising two search queries (see Table 1):

- The specific search (A) used MeSH terms to search for CPOE-related articles.

- The topical search (B) on the general term "CPOE" discovered CPOE-related articles that have not been $\mathrm{MeSH}$-indexed so far.

To reduce the number of hits, these two CPOErelated terms were combined with keywords regarding the alert optimization, alert number, and alert response (see Table 1).

Both researchers individually reviewed the abstracts of the found articles. Irrelevant papers were excluded if they did not contain any ideas that could be used for contextualized prioritization of CPOE alerts. All the relevant articles were included for full-text review and again read individually by both researchers. In order to extract possible context factors the researchers looked for correlations between the rates of overridden alerts and specific variables, for example, the number of years a doctor worked in the healthcare organization [19]. Furthermore, ideas for context factors were extracted if the authors of the papers suggested to tailor the alerts according to certain factors (for example, the complexity of the clinical case [20]) or aimed to increase the specificity and sensitivity of alerts by certain 'contextual' adaptations [12].

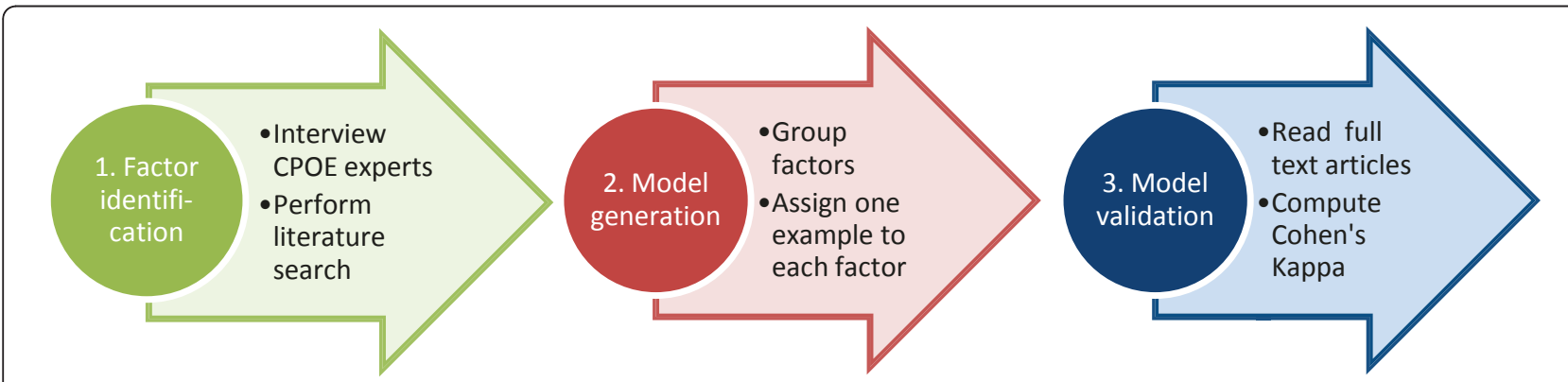

Figure 2 Major phases in the development and validation of the context model. 
Table 1 Search terms for the factor extraction phase

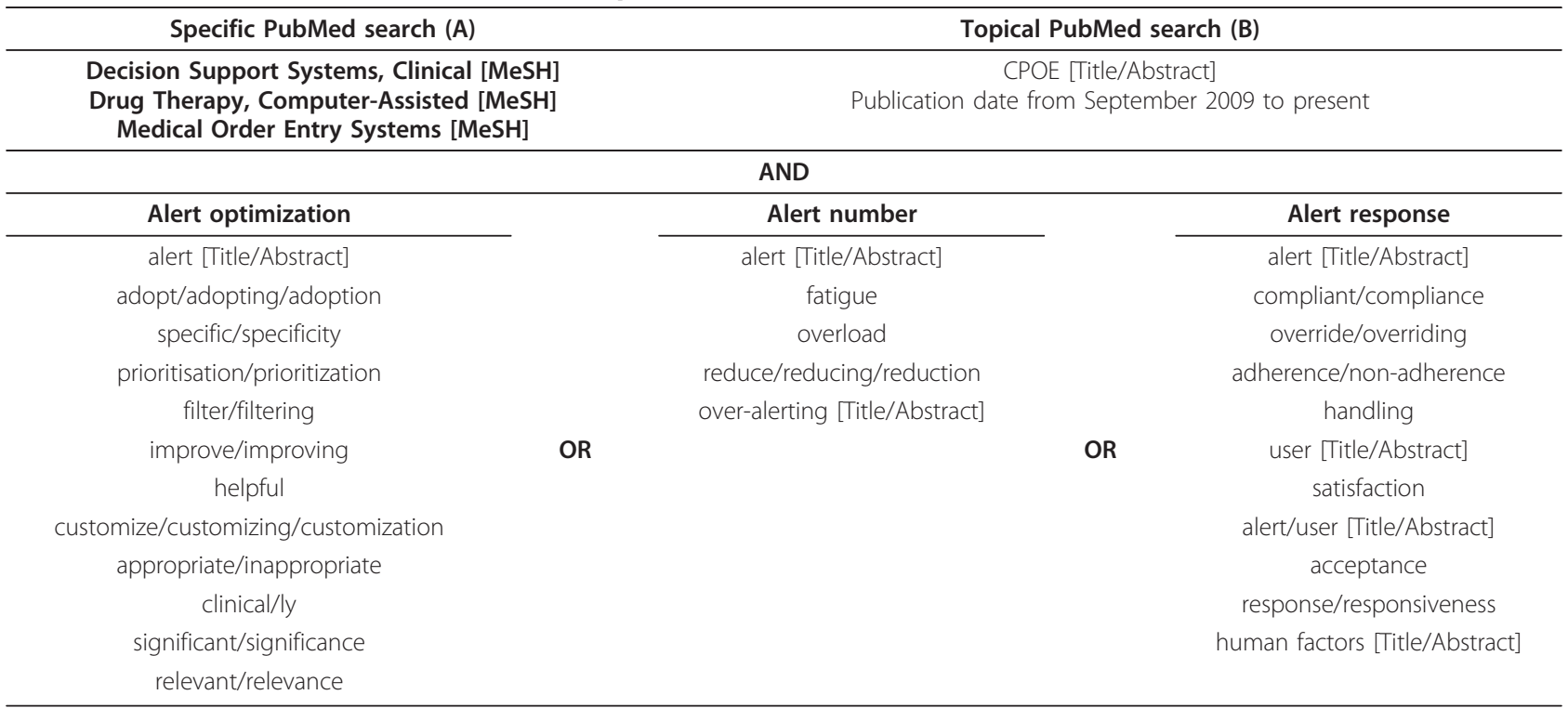

MeSH terms are in bold.

A detailed flowchart of the performed literature search is shown in the following illustration (see Figure 3).

\section{Expert interviews}

We performed qualitative interviews with leading international experts in the field of CPOE. We created a ranked list of experts on the basis of their number of publications as first named authors regarding CPOE-related papers (using the search terms "CPOE" in all fields and "medical order entry systems", "computer-assisted drug therapy", and "clinical decision support system" as major MeSHheadings within PubMed). First, we invited the authors with the most publications. We planned five interviews as a minimum and intended to conduct more interviews depending on the level of saturation, which means that data are collected until no new information can be retrieved [21]. In the end we conducted five interviews. Saturation was reached as the interviewed experts did not identify any new factors. When selecting the interview partners, we took care to ensure that none of them had any direct affiliation with the PSIP project.

The expert interviews were conducted using a semistructured interview guideline. The interviewees were informed in advance by a description of our concept (cf. description of Figure 1) and the main interview question:

"Question: What could be the most important context factors that can be used for the prioritization of alerts?"

The telephone interviews were planned to take about 20 minutes. All the interviews were recorded and transcribed using summarized conversation protocols.

\section{Phase 2: Generation of context model}

The extracted context factors from the literature search and the semi-structured interviews were generalized and hierarchically organized. To organize the factors we made use of an inductive category development according to Mayring [22]. Furthermore, for each context factor a generic definition and a specific example was generated. To collaboratively develop this context model we used an online brainstorming and mind map modeling tool.

\section{Phase 3: Validation of context model}

The research team performed a first internal validation. Both researchers (MJ and DR) read all of the 33 full text articles that were found. Passages within those papers that indicated the contextualization of drug safety alerts were then independently classified using the final context model. The inter-researcher agreement for all text passages discovered by both researchers was determined by computing Cohen's Kappa coefficient. Disagreements in the classifications were put to discussion.

\section{Results}

\section{The context model}

The final context model is the result of the performed literature search and the five semi-structured expert interviews. In the interviews, five CPOE experts (having published between 3 and 13 CPOE-related articles on PubMed) agreed to participate (three from North America and two from Europe). They mentioned 12 possible context factors. In the literature search, 33 papers were identified that named 20 possible context factors, including the 12 factors named by the experts. 


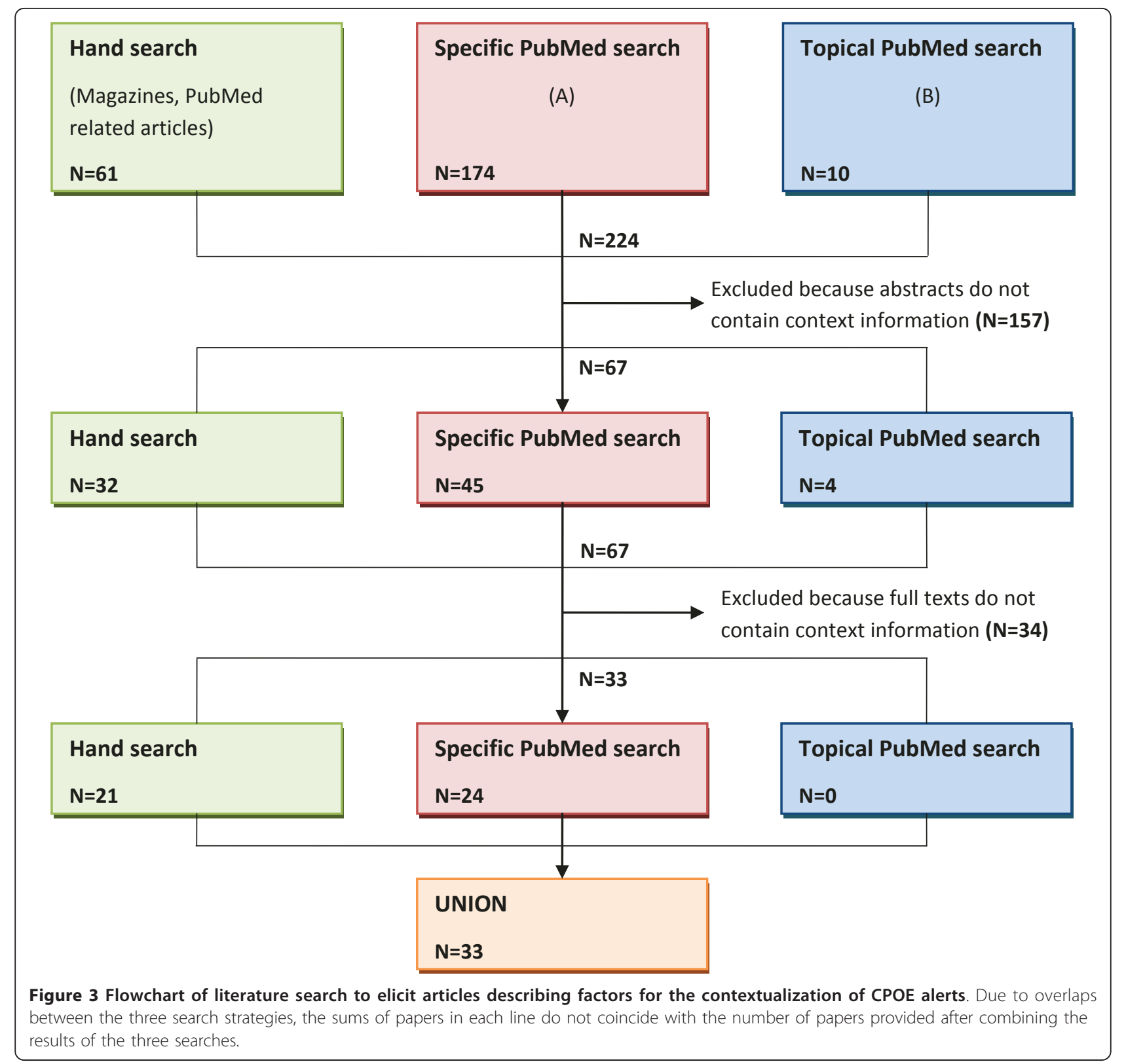

Table 2 lists all the identified context factors, together with an explanation. The found 20 context factors are grouped into three main categories (see also Figure 4).

\section{Characteristics of the organizational unit}

Drug safety alerts can be prioritized based on the characteristics of the organizational unit. These context factors can affect three organization levels of health care: the entire hospital, a special hospital department, or an individual CPOE user. For example, certain types of alerts may be disabled for a specialized department, or a user with a lot of experience may want less intrusive alerts for a special group of drugs.

2. Characteristics of the patient/case

Information on the patient case can help to improve the tailoring of warnings. For example, recent lab values or known diagnoses may be taken into account when prioritizing alerts.

3. Characteristics of the alert

Warnings in CPOE systems can also be contextualized on the basis of alert characteristics. For example, alerts pointing to the possibility of less serious ADEs may be presented in a less intrusive way. 
Table 2 List of extracted context factors including definition and one example for each factor

\begin{tabular}{|c|c|c|}
\hline & Definition & Example \\
\hline & $\begin{array}{l}\text { ADE rate of the department/hospital } \\
\text { The total number of ADEs which occur in the } \\
\text { department/hospital. }\end{array}$ & $\begin{array}{l}\text { If a department/hospital has a low rate of a specific ADE, don't show } \\
\text { the corresponding alerts. }\end{array}$ \\
\hline & $\begin{array}{l}\text { Population of the hospital } \\
\text { The epidemiological characteristics of the patient } \\
\text { population from the geographical catchment area of the } \\
\text { hospital. }\end{array}$ & $\begin{array}{l}\text { Show more alerts for increased risk of liver destruction when the } \\
\text { prevalence for liver diseases is high in the area of the hospital. }\end{array}$ \\
\hline & $\begin{array}{l}\text { Professional experience of the user } \\
\text { Years of working experience; degree and the position in } \\
\text { the hierarchy. }\end{array}$ & A senior physician receives fewer alerts than a resident. \\
\hline & $\begin{array}{l}\text { Repetition of alerts } \\
\text { The number of times a specific alert is presented to the } \\
\text { user. }\end{array}$ & $\begin{array}{l}\text { An alert is only shown to a doctor once a day or an alert is never } \\
\text { shown twice for the same patient (e.g. after renewal of a prescription) }\end{array}$ \\
\hline \multirow[t]{6}{*}{$\begin{array}{l}\text { Organizational } \\
\text { unit }\end{array}$} & $\begin{array}{l}\text { Current task of the user } \\
\text { The current step in the medication workflow } \\
\text { (prescription, dispensation, administration). }\end{array}$ & $\begin{array}{l}\text { Show all alerts during prescription, but only the most severe alerts } \\
\text { during administration. }\end{array}$ \\
\hline & $\begin{array}{l}\text { Personal preferences of the user } \\
\text { Individual customization of the alerts depending on the } \\
\text { user's needs or preferences. }\end{array}$ & A doctor can turn off certain alerts if he or she doesn't want them. \\
\hline & $\begin{array}{l}\text { Override-rate of alerts } \\
\text { The frequency a specific alert gets overridden by a } \\
\text { specific user or department-/hospital-wide. }\end{array}$ & $\begin{array}{l}\text { An alert won't be shown again to a doctor if he/she has already } \\
\text { overridden it several times. }\end{array}$ \\
\hline & $\begin{array}{l}\text { Specialty } \\
\text { The specialist field of the user or the special field of the } \\
\text { department/hospital. }\end{array}$ & A psychiatrist receives different alerts than a surgeon. \\
\hline & $\begin{array}{l}\text { Workload } \\
\text { The number of patients to care for, the staffing of the } \\
\text { department, the duration of the shift or the time of the } \\
\text { day. }\end{array}$ & $\begin{array}{l}\text { Certain alerts that might be overlooked should be highlighted when } \\
\text { the doctor is working for more than } 8 \mathrm{~h} \text {. }\end{array}$ \\
\hline & $\begin{array}{l}\text { Demographic data of the patient } \\
\text { The sex, age and ethnicity of the patient. }\end{array}$ & Show certain alerts only for patients older than 60 years. \\
\hline \multirow[t]{5}{*}{ Patient/Case } & $\begin{array}{l}\text { Risk factors of the patient } \\
\text { A certain genetic disposition, alcoholism, obesity or } \\
\text { under-nutrition. }\end{array}$ & Show specific alerts only for alcoholics. \\
\hline & $\begin{array}{l}\text { Tolerance of the drug } \\
\text { The case history of the patient shows that he/she } \\
\text { tolerates a drug. }\end{array}$ & $\begin{array}{l}\text { Don't show alerts for the possible side effects of aspirin, if the patient } \\
\text { hasn't developed any of these in a previous case. }\end{array}$ \\
\hline & $\begin{array}{l}\text { Complexity of the case } \\
\text { The number of clinical conditions and multi-morbidities } \\
\text { of a patient or the number of applied drugs. }\end{array}$ & $\begin{array}{l}\text { Certain alerts that might be overlooked should be highlighted in case } \\
\text { that the patient has more than } 5 \text { chronic clinical conditions or if he } \\
\text { takes more than } 5 \text { different drugs at the same time. }\end{array}$ \\
\hline & $\begin{array}{l}\text { Clinical status of the patient } \\
\text { The type of disease, the severity or stadium of the } \\
\text { disease or clinical parameters (e.g. lab values). }\end{array}$ & $\begin{array}{l}\text { Show specific alerts only if the patient suffers from renal diseases or } \\
\text { when a lab value reaches a critical threshold. }\end{array}$ \\
\hline & $\begin{array}{l}\text { Class of drug } \\
\text { The group of the prescribed drug (e.g. narcotics, } \\
\text { anticoagulants) relating to the possible damage it may } \\
\text { cause. }\end{array}$ & $\begin{array}{l}\text { Highlight specific alerts only for classes of drugs with a high ADE } \\
\text { potential (e.g. corticosteroids). }\end{array}$ \\
\hline \multirow[t]{5}{*}{ Alert } & $\begin{array}{l}\text { Severity of the effect } \\
\text { The seriousness of the potential effect. }\end{array}$ & $\begin{array}{l}\text { Don't show alerts when the expected effect may cause no or only } \\
\text { minor patient harm. }\end{array}$ \\
\hline & $\begin{array}{l}\text { Probability of occurrence } \\
\text { The probability of occurrence of the expected ADE. }\end{array}$ & $\begin{array}{l}\text { When prescribing an anticoagulant, show an alert only if the } \\
\text { probability of internal bleeding is higher than } 5 \% \text {. }\end{array}$ \\
\hline & $\begin{array}{l}\text { Strength of evidence } \\
\text { The strength of the scientific evidence of a certain effect. }\end{array}$ & $\begin{array}{l}\text { Don't show alerts if only one non-randomized study reports this } \\
\text { certain effect. }\end{array}$ \\
\hline & $\begin{array}{l}\text { Topicality of the alert } \\
\text { How long a certain alert is in the system or the time } \\
\text { since the last update of an alert. }\end{array}$ & Highlight alerts that are new in the system. \\
\hline & $\begin{array}{l}\text { Type of alert } \\
\text { The type of drug interaction (e.g. drug-drug interaction, } \\
\text { drug-allergy interaction) that may occur. }\end{array}$ & $\begin{array}{l}\text { Don't show drug-allergy alerts if allergies are not sufficiently } \\
\text { documented in the patient records of the hospital. }\end{array}$ \\
\hline
\end{tabular}




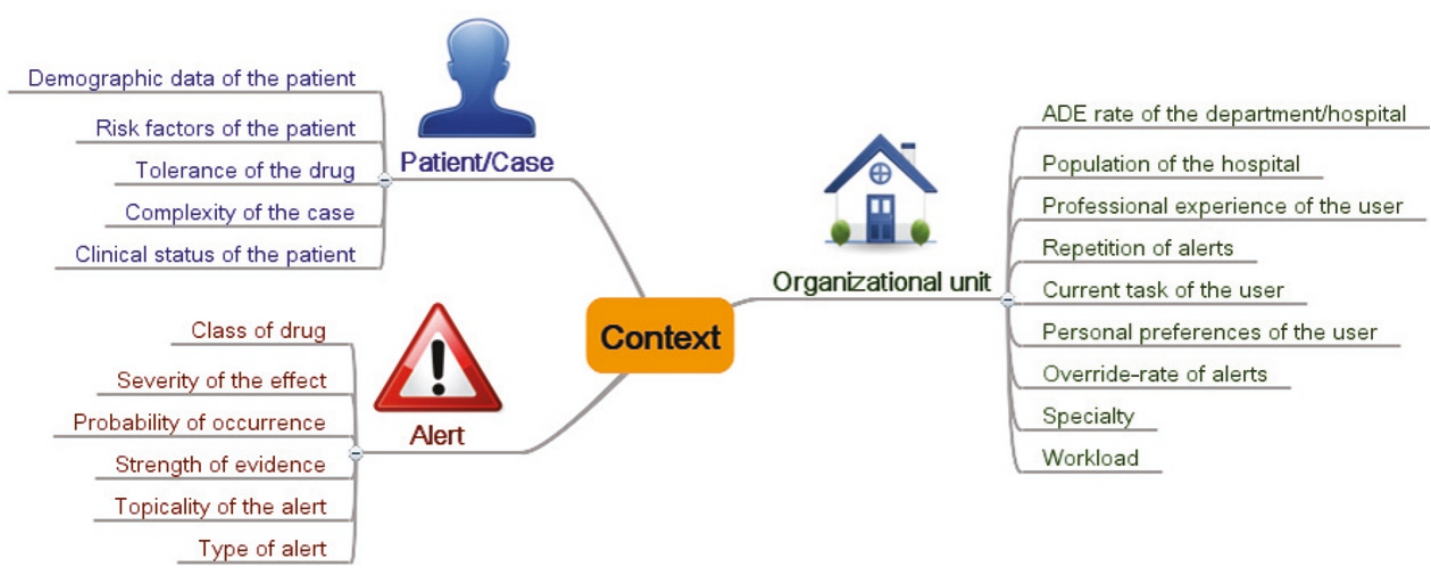

Figure 4 Mind map of the final context model grouped in three categories.

\section{Support for each context factor}

From the 33 full text articles that were judged to be relevant in the literature search, the researchers identified an overall number of 133 text passages indicating the contextualization of drug safety alerts. Table 3 gives an overview of the number of text passages per context factors, with each passage either supporting or opposing a factor. Table 4 gives an overview of the 12 factors mentioned in the expert interviews.

\section{Internal model validation}

Of those mutually found 133 text passages, 100 were individually found by both researchers (MJ and DR). For these 100 text passages, Cohen's Kappa was $\kappa=0.97$ (for details see additional files).

\section{Discussion}

\section{Answer to the study question}

Based on a broad literature search and expert interviews, we identified 20 factors that could be used to

Table 3 Literature support for each factor of the context model

\begin{tabular}{|c|c|c|c|c|}
\hline & Context factor & Pros (+) & Cons (-) & $\mathrm{N}$ \\
\hline & ADE rate of the department/hospital & {$[12,27]$} & & 2 \\
\hline & Population of the hospital & {$[15]$} & & 1 \\
\hline & Professional experience of the user & {$[12,15,20,23,24,27-31]$} & {$[12,19]$} & 12 \\
\hline \multirow[t]{8}{*}{ Organizational unit } & Repetition of alerts & {$[11,12,14,20,27,29,31-35]$} & & 11 \\
\hline & Current task of the user & {$[11,14,19,33]$} & & 4 \\
\hline & Personal preferences of the user & {$[15,27,31,36,37]$} & {$[31,34]$} & 7 \\
\hline & Override-rate of alerts & {$[11,15,31]$} & & 3 \\
\hline & Specialty & {$[11,12,15,23,27,28,38]$} & {$[35]$} & 8 \\
\hline & Workload & {$[12,19,39]$} & {$[29]$} & 4 \\
\hline & Demographic data of the patient & {$[12,19,20,27,29-31,37,38,40]$} & {$[29,35]$} & 12 \\
\hline & Risk factors of the patient & {$[12,24]$} & & 2 \\
\hline \multirow[t]{4}{*}{ Patient/Case } & Tolerance of the drug & {$[12,15,20,31,35-37,40,41]$} & & 9 \\
\hline & Complexity of the case & {$[19,20,37,40]$} & [35] & 5 \\
\hline & Clinical status of the patient & {$[12,19,27,29,33,35,37,38]$} & & 8 \\
\hline & Class of drug & {$[15,31,35,40,42]$} & [41] & 6 \\
\hline \multirow[t]{6}{*}{ Alert } & Severity of the effect & {$[11,12,20,24,31,35,40,41,43-46]$} & {$[12,23,31,33,37,46]$} & 18 \\
\hline & Probability of occurrence & {$[24,44]$} & & 2 \\
\hline & Strength of evidence & {$[11,20,24,27,33,40,47]$} & & 7 \\
\hline & Topicality of the alert & {$[28,41]$} & & 2 \\
\hline & Type of alert & {$[12,20,35,40,41,48-50]$} & {$[19,51]$} & 10 \\
\hline & & & $\Sigma$ & 133 \\
\hline
\end{tabular}

"Pros" are references which positively discuss the given factor. "Cons" are references which negatively discuss the given factor. $\mathrm{N}$ gives the overall number of cases a factor has been discussed. 


\begin{tabular}{|c|c|}
\hline Context factor & $\mathrm{N}$ \\
\hline \multicolumn{2}{|l|}{ Organizational unit } \\
\hline Personal preferences of the user & 2 \\
\hline Specialty & 2 \\
\hline Current task of the user & 1 \\
\hline Override-rate of alerts & 1 \\
\hline Repetition of alerts & 1 \\
\hline \multicolumn{2}{|l|}{ Patient/Case } \\
\hline Clinical status of the patient & 4 \\
\hline Demographic data of the patient & 4 \\
\hline Risk factors of the patient & 1 \\
\hline Complexity of the case & 1 \\
\hline Tolerance of the drug & 1 \\
\hline \multicolumn{2}{|l|}{ Alert } \\
\hline Severity of the effect & 3 \\
\hline Strength of evidence & 1 \\
\hline & 22 \\
\hline
\end{tabular}

$\mathrm{N}$... Number of interviewees who mentioned the context factor

contextualize drug safety alerts in CPOE systems. From the final 20 factors, 12 were mentioned during the expert interviews. Most factors that were named by more than one expert were also more intensively discussed in the literature (cf. Table 3 and Table 4). A possible explanation for this might be that there was an overlap between the authors of the papers found in the literature search and the CPOE experts invited for the telephone interviews (three out of five interviewees also appeared as authors of analysed papers).

\section{Strengths and weaknesses of the study}

As strength, we combined interviews with a literature search during the development of the context model (cf. Figure 2). A literature search, which does not claim to be a systematic review, dominated the phase of factor extraction. We neither rated the type of article (RCT versus opinion paper) nor the section where the context information was gathered from (e.g. result vs. discussion). We cannot be sure that we identified all context factors ever discussed in the literature. However, as the interviewed experts did not identify other factors that we have found in the literature search, our list sufficiently reflects the state of scientific discussion at the moment.

The validation of the context model was conducted by the same two researchers who were involved in the model creation. This might explain the high Cohen's Kappa value of 0.97. Disagreements occurred in cases where the definitions of context factors only differ slightly. For instance, the definition of the factors 'repetition of alerts' (same alert shown frequently to the same user) and 'override-rate of alerts' (alerts overridden frequently by one user/all users from one department/all users from the hospital) only differ in the action the user takes when the alert is triggered (cf. Table 2). This could be seen in one non-agreement (see additional files).

We grouped the found 20 factors into three categories - naturally, other ways of groupings would be possible.

The final context model includes factors that differ in the level of abstraction. While the definitions of some context factors are very narrow (e.g. override-rate of alerts), others are more general (e.g. clinical status of the patient). This mostly reflects the different level of detail of the discussion in the literature, but also points to the need to limit the number of context factors by aggregating them.

No formal validation of completeness or external validation of the context model has been done yet.

\section{Results in relation to other studies}

According to our knowledge, the developed context model is the first attempt to systematically reveal and structure 'context' that can be used for the prioritization of drug safety alerts. Some of the factors have been used within suggestions for alert improvement. For instance, van der Sijs et al. [23] (p.446) suggested that drug safety alerts might be improved if they were customized to professional experience, but also warned about turning off alerts for experts because of errors due to lack of attention, distraction, and forgetfulness. Sittig et al. [19], however, concluded in his study that there was no indication that users of different level of experience differed in their decisions to accept or ignore various CDS features. This example shows that tailoring alerts according to the professional experience is not consistently seen in the literature. A promising approach from our point of view is to tier alerts according to the level of severity which is, among others, also pursued by Paterno et al. [24]. She concluded that a tiered presentation of DDI alerts led to higher compliance rates of the physicians. A potential way to determine the level of severity of an alert is provided by the 'Medication Error Index' by the National Coordinating Council for Medication Error Reporting and Prevention, which provides a classification according to the severity of the outcome of a medication error [25]. Further studies are needed to better understand the feasibility of using each context factor for alert optimization, as well as the effect when using it.

\section{Meaning and generalizability of the study}

The serious problem of alert overload causing alert fatigue and the ways to improve drug safety alerting in CPOE systems is a current issue [14]. 
Some of the presented context factors are already in use or may be considered in the development of future CPOE and CDS systems. For instance, within the PSIP project, the CDS system uses information on the diagnosis and lab values of a patient to trigger drug safety alerts.

However, for the implementation of several context factors into a real-world scenario, multiple preconditions have to be fulfilled in advance. For example, organizational (e.g. unique drug naming, international druginteraction database, etc.), technical (e.g. data integration, standardization, etc.), and human (e.g. physicians' acceptance, etc.) aspects have to be taken into account.

The long-term experience with the Dutch drug database G-standard is now being used in the International Health Terminology Standards Development Organisation (IHTSDO) for the development of a good structure and unequivocal pharmaceutical information in SNOMED CT (Systematized Nomenclature of Medicine-Clinical Terms). In many countries, different commercial databases are used, and people are afraid of turning off alerts because of legal consequences. A shared international database could probably be used as a professional standard for those alerts that should be generated and those that can be turned off [23].

With respect to human factors, however, much is still unknown. It is unclear as to how the alerts of different severity and type (drug-interaction, duplicate order, or overdose) should be presented to the user (which colors, which form, which place on the screen, and whether visual or auditory signals should be used). The preferred order and length of the text components in the alert text is unknown, and which information should be available only in the background.

\section{Unanswered and new questions}

The identified set of context factors for alert prioritization is proposed as a starting point for effective alerting in CPOE systems. At the moment, however, it is unclear which of the presented 20 context factors should be taken into account when triggering a drug safety alert. To address this unanswered question, a user survey among European physicians and a Delphi study among international CPOE experts has been conducted [26].

Another issue that should be dealt with in the future is the most effective combination of context factors. This could be subject of an international multi-disciplinary workshop of CPOE experts, users (physicians and pharmacists) as well as industry partners. The effectiveness should then be evaluated in subsequent experimental studies.

\section{Conclusion}

To our knowledge, this is the first attempt to structure and validate possible context factors for alert optimization within CPOE systems. The ideas and concepts that have evolved throughout this work need further validation and clinical evaluation.

\section{Additional material}

\section{Additional file 1: List of hand-searched journals \\ Additional file 2: Cohen's Kappa for context model. Inter-researcher agreement for 100 text passages indicating the contextualization of drug safety alerts that were individually found by the researchers.}

\section{Acknowledgements}

We would like to thank all of the international experts for actively contributing to this research. The authors gratefully acknowledge the assistance of the following individuals who made valuable contributions to the development of the context model: Martina Jeske and Johannes Anzengruber.

The research leading to these results has received funding from the European Community's Seventh Framework Programme (FP7/2007-2013) under grant agreement no. 216130.

\section{Author details}

${ }^{1}$ Institute of Health Informatics, UMIT - University for Health Sciences, Medical Informatics and Technology, Eduard Wallnöfer-Zentrum I, Hall in Tirol, Austria. ${ }^{2}$ Department for Public Health and HTA, UMIT - University for Health Sciences, Medical Informatics and Technology, Eduard WallnöferZentrum I, Hall in Tirol, Austria. ${ }^{3}$ Department of Hospital Pharmacy, Erasmus University Medical Centre, P.O. Box 2040, 3000 CA Rotterdam, Netherlands.

\section{Authors' contributions}

DR and MJ carried out the literature search, performed the expert interviews, developed the context model, and accomplished the internal validation of the model. Furthermore, they drafted and revised the manuscript. WOH, WS and EA further refined the definitions and examples of the context factors. $\mathrm{WOH}$ and EA additionally participated in the development of the categories during the generation of the context model. WS and HS critically revised the manuscript and added an external point of view mainly in the discussion section. All authors read and approved the final manuscript.

\section{Competing interests}

The authors declare that they have no competing interests.

Received: 4 February 2011 Accepted: 25 May 2011

Published: 25 May 2011

\section{References}

1. Byers JF, White SV: Patient safety: principles and practice. New York, NY: Springer; 2004

2. Institute of Medicine - Committee on Identifying and Preventing Medication Errors: Preventing medication errors.Edited by: Aspden $\mathrm{P}$ Wolcott JA, Bootman JL, Cronenwett LR. Washington, DC: National Academies Press; 2007:

3. Council of Europe, Committee of Experts on Management of Safety and Quality in Health Care (SP-SQS) - Expert Group on Safe Medication Practices: Glossary of terms related to patient and medication safety. Strasbourg: Council of Europe; 2005 [http://www.who.int/patientsafety/ highlights/COE_patient_and_medication_safety_gl.pdf], [document on the Internet] [updated 10 Oct 2005; cited 20 May 2010].

4. USP: Medication Use Process. Rockville, MD: United States Pharmacopeia; 2004 [http://www.usp.org/pdf/EN/patientSafety/medicationUseProcess.pdf], [document on the Internet] [updated 2004; cited 2010 May 27].

5. Bates DW, Cullen DJ, Laird N, Petersen LA, Small SD, Servi D, et al: Incidence of adverse drug events and potential adverse drug events. Implications for prevention. ADE Prevention Study Group. JAMA 1995, 274(1):29-34

6. Benkirane RR, Abouqal R, Haimeur CC, SS SECEK, Azzouzi AA, M'Daghri Alaoui $A A$, et al: Incidence of adverse drug events and medication errors 
in intensive care units: a prospective multicenter study. J Patient Saf 2009, 5(1):16-22.

7. Reckmann MH, Westbrook JI, Koh Y, Lo C, Day RO: Does computerized provider order entry reduce prescribing errors for hospital inpatients? A systematic review. J Am Med Inform Assoc 2009, 16(5):613-23.

8. Ammenwerth E, Schnell-Inderst P, Machan C, Siebert U: The effect of electronic prescribing on medication errors and adverse drug events: a systematic review. J Am Med Inform Assoc 2008, 15(5):585-600.

9. Hug BL, Witkowski DJ, Sox CM, Keohane CA, Seger DL, Yoon C, et al: Adverse drug event rates in six community hospitals and the potential impact of computerized physician order entry for prevention. J Gen Intern Med 2010, 25(1):31-8.

10. van Doormaal JE, van den Bemt PM, Zaal RJ, Egberts AC, Lenderink BW, Kosterink JG, et al: The influence that electronic prescribing has on medication errors and preventable adverse drug events: an interrupted time-series study. J Am Med Inform Assoc 2009, 16(6):816-25.

11. Kuperman GJ, Bobb A, Payne TH, Avery AJ, Gandhi TK, Burns G, et al: Medication-related clinical decision support in computerized provider order entry systems: a review. J Am Med Inform Assoc 2007, 14(1):29-40.

12. van der Sijs H, Aarts J, Vulto A, Berg M: Overriding of drug safety alerts in computerized physician order entry. J Am Med Inform Assoc 2006, 13(2):138-47.

13. Ash JS, Sittig DF, Campbell EM, Guappone KP, Dykstra RH: Some unintended consequences of clinical decision support systems. AMIA Annu Symp Proc 2007, 26-30.

14. Khajouei $R$, Jaspers MW: The impact of CPOE medication systems' design aspects on usability, workflow and medication orders: a systematic review. Methods Inf Med 2010, 49(1):3-19.

15. Cash JJ: Alert fatigue. Am J Health Syst Pharm 2009, 66(23):2098-101.

16. van der Sijs H: Drug Safety Alerting in Computerized Physician Order Entry: Unraveling and Counteracting Alert Fatigue. [Dissertation]. Rotterdam: Erasmus University Rotterdam; 2009 [http://publishing.eur.nl/ir/ repub/asset/16936/090902_Sijs, Ida Helene van der.pdf].

17. Dey AK: Understanding and Using Context. Personal and Ubiquitous Computing. 2001, 5(1):4-7[http://www.cc.gatech.edu/fce/ctk/pubs/PeTe5-1.pdf].

18. Beuscart $R, M c N a i r P$, Brender J: Patient safety through intelligent procedures in medication: the PSIP project. Stud Health Technol Inform 2009, 148:6-13.

19. Sittig DF, Krall MA, Dykstra RH, Russell A, Chin HL: A survey of factors affecting clinician acceptance of clinical decision support. BMC Med Inform Decis Mak 2006, 6:6

20. Weingart SN, Toth M, Sands DZ, Aronson MD, Davis RB, Phillips RS: Physicians' decisions to override computerized drug alerts in primary care. Arch Intern Med 2003, 163(21):2625-31.

21. Strauss AL, Corbin JM: Basics of qualitative research: techniques and procedures for developing grounded theory. Thousand Oaks: Sage Publications; 21998.

22. Mayring P: Qualitative Content Analysis [28 paragraphs]. Forum: Qualitative Social Research [serial on the Internet] 2000, 1(2)[http://www. qualitative-research.net/index.php/fqs/article/view/1089/2385], [cited 2010 Aug 23].

23. van der Sijs H, Aarts J, van Gelder T, Berg M, Vulto A: Turning off frequently overridden drug alerts: limited opportunities for doing it safely. J Am Med Inform Assoc 2008, 15(4):439-48.

24. Paterno MD, Maviglia SM, Gorman PN, Seger DL, Yoshida E, Seger AC, et al: Tiering drug-drug interaction alerts by severity increases compliance rates. J Am Med Inform Assoc 2009, 16(1):40-6.

25. NCC MERP: Index for Categorizing Medication Errors. [document on the Internet] Rockville, MD: National Coordinating Council for Medication Error Reporting and Prevention; 2001 [http://www.nccmerp.org/pdf/ indexColor2001-06-12.pdf], [updated 20 Feb 2001; cited 24 Mar 2011].

26. Riedmann D, Jung M, Hackl W, Stühlinger W, Ammenwerth E: Prioritization of alerts in CPOE systems using the clinical context - A mixed method study.Edited by: Schmücker P, Ellsässer KH, Hayna S. Mannheim; 2010:362-3, 55th annual meeting of the GMDS.

27. Krall MA, Sittig DF: Clinician's assessments of outpatient electronic medical record alert and reminder usability and usefulness requirements. Proc AMIA Symp 2002, 400-4.

28. Oppenheim MI, Mintz RJ, Boyer AG, Frayer WW: Design of a clinical alert system to facilitate development, testing, maintenance, and user-specific notification. Proc AMIA Symp 2000, 630-4.
29. Galanter WL, Didomenico RJ, Polikaitis A: A trial of automated decision support alerts for contraindicated medications using computerized physician order entry. J Am Med Inform Assoc 2005, 12(3):269-74.

30. Raebel MA, Charles J, Dugan J, Carroll NM, Korner EJ, Brand DW, et al: Randomized trial to improve prescribing safety in ambulatory elderly patients. J Am Geriatr Soc 2007, 55(7):977-85.

31. Grizzle AJ, Mahmood MH, Ko Y, Murphy JE, Armstrong EP, Skrepnek GH, et al: Reasons provided by prescribers when overriding drug-drug interaction alerts. Am J Manag Care 2007, 13(10):573-8.

32. Abookire SA, Teich JM, Sandige H, Paterno MD, Martin MT, Kuperman GJ, et al: Improving allergy alerting in a computerized physician order entry system. Proc AMIA Symp 2000, 2-6.

33. Bates DW, Kuperman GJ, Wang S, Gandhi T, Kittler A, Volk L, et al: Ten commandments for effective clinical decision support: making the practice of evidence-based medicine a reality. J Am Med Inform Assoc 2003, 10(6):523-30.

34. Feldstein A, Simon SR, Schneider J, Krall M, Laferriere D, Smith DH, et al: How to design computerized alerts to safe prescribing practices. $J t$ Comm J Qual Saf 2004, 30(11):602-13.

35. Isaac T, Weissman JS, Davis RB, Massagli M, Cyrulik A, Sands DZ, et al: Overrides of medication alerts in ambulatory care. Arch Intern Med 2009, 169(3):305-11.

36. Lapane KL, Waring ME, Schneider KL, Dube C, Quilliam BJ: A mixed method study of the merits of e-prescribing drug alerts in primary care. J Gen Intern Med 2008, 23(4):442-6.

37. Tamblyn R, Huang A, Taylor L, Kawasumi Y, Bartlett G, Grad R, et al: A randomized trial of the effectiveness of on-demand versus computertriggered drug decision support in primary care. J Am Med Inform Assoc 2008, 15(4):430-8.

38. Miyo K, Nittami YS, Kitagawa Y, Ohe K: Development of case-based medication alerting and recommender system: a new approach to prevention for medication error. Stud Health Technol Inform 2007, 129(Pt 2):871-4.

39. Kucher N, Puck M, Blaser J, Bucklar G, Eschmann E, Luscher TF: Physician compliance with advanced electronic alerts for preventing venous thromboembolism among hospitalized medical patients. J Thromb Haemost 2009, 7(8):1291-6.

40. Hsieh TC, Kuperman GJ, Jaggi T, Hojnowski-Diaz P, Fiskio J, Williams DH, et al: Characteristics and consequences of drug allergy alert overrides in a computerized physician order entry system. J Am Med Inform Assoc 2004, 11(6):482-91.

41. Shah NR, Seger AC, Seger DL, Fiskio JM, Kuperman GJ, Blumenfeld B, et al: Improving acceptance of computerized prescribing alerts in ambulatory care. J Am Med Inform Assoc 2006, 13(1):5-11.

42. Judge J, Field TS, DeFlorio M, Laprino J, Auger J, Rochon P, et al: Prescribers' responses to alerts during medication ordering in the long term care setting. J Am Med Inform Assoc 2006, 13(4):385-90.

43. Eslami S, de Keizer NF, Abu-Hanna A: The impact of computerized physician medication order entry in hospitalized patients-a systematic review. Int J Med Inform 2008, 77(6):365-76.

44. Luna D, Otero V, Canosa D, Montenegro S, Otero P, de Quiros FG: Analysis and redesign of a knowledge database for a drug-drug interactions alert system. Stud Health Technol Inform 2007, 129(Pt 2):885-9.

45. Gross PA, Bates DW: A pragmatic approach to implementing best practices for clinical decision support systems in computerized provider order entry systems. J Am Med Inform Assoc 2007, 14(1):25-8.

46. Magnus D, Rodgers S, Avery AJ: GPs' views on computerized drug interaction alerts: questionnaire survey. J Clin Pharm Ther 2002, 27(5):377-82.

47. Xie $M$, Johnson $K$ : Applying human factors research to alert-fatigue in eprescribing. AMIA Annu Symp Proc 2007, 1161.

48. van der Sijs H, Mulder A, van Gelder T, Aarts J, Berg M, Vulto A: Drug safety alert generation and overriding in a large Dutch university medical centre. Pharmacoepidemiol Drug Saf 2009, 18(10):941-7.

49. Stutman HR, Fineman R, Meyer K, Jones D: Optimizing the acceptance of medication-based alerts by physicians during CPOE implementation in a community hospital environment. AMIA Annu Symp Proc 2007, 701-5.

50. Shah NR, Seger AC, Seger DL, Fiskio JM, Kuperman GJ, Blumenfeld B, et al: Improving override rates for computerized prescribing alerts in ambulatory care. AMIA Annu Symp Proc 2005, 1110. 
51. Krall MA, Sittig DF: Subjective assessment of usefulness and appropriate presentation mode of alerts and reminders in the outpatient setting. Proc AMIA Symp 2001, 334-8.

\section{Pre-publication history}

The pre-publication history for this paper can be accessed here:

http://www.biomedcentral.com/1472-6947/11/35/prepub

doi:10.1186/1472-6947-11-35

Cite this article as: Riedmann et al: Development of a context model to prioritize drug safety alerts in CPOE systems. BMC Medical Informatics and Decision Making 2011 11:35.

Submit your next manuscript to BioMed Central and take full advantage of:

- Convenient online submission

- Thorough peer review

- No space constraints or color figure charges

- Immediate publication on acceptance

- Inclusion in PubMed, CAS, Scopus and Google Scholar

- Research which is freely available for redistribution

Submit your manuscript at www.biomedcentral.com/submit 